\title{
The Quest for Multilingualism at the Center in the Ethiopian Federation and the Challenges of Entertainment
}

\author{
Abiy Wondimeneh Lissanework \\ Lecturer, Department of Civics and Ethical Studies, Ambo University, Ethiopia
}

\begin{abstract}
Language is one of the various federal issues that have not yet been adequately addressed and continued to be an issue of contention between the centripetal and centrifugal forces in the Ethiopian federal system. As such, it is not only the fact of multilingualism that characterizes the federal setting in Ethiopia today; but also a political odd based on language differences that needs due attention. After more than two decades of history as a federation, there is a contention regarding the working language at the federal level and a demand for the recognition of other languages at the center. In this piece it is contended that, within the context of highly institutionalized ethnic politics like the one in Ethiopia, recognizing another local language as a federal working language would not resolve the political odd surrounding language; rather it would simply lead to similar other demands that could be hardly entertained. Hence, considering an alien language, particularly English, as the working language of the federal government by revoking the language currently serving such a purpose could possibly solve the political quagmire surrounding language and would also make the country better equipped to benefit from the global capital market.
\end{abstract}

Keywords: Ethiopia, Federalism, Language policy, Multilingualism

\section{INTRODUCTION}

Language functions not only as a means of communication, but also as an important part of one's personal identity and sense of belonging, making the status and recognition accorded to one's language affect one's self-esteem (Seidel and Moritz, 2009). Hence, there are often disputes surrounding language in multilingual societies that bring to the fore various issues of multiculturalism like equality, recognition, freedom, identity, democracy, and cultural preservation (Patten, 2001). As such, one of the critical issues to be addressed in the political organization and constitutional design of multicultural societies is the issue of language for the reason that people consider their language as one of the defining elements of their identity. Moreover, language remains to be one of the most contested forces in multiethnic and multilingual societies for it affects citizens' access to education, employment, and political participation (Kanana, 2013). Today, each multilingual country having its own unique set of characteristics, there are almost 7000 languages in daily use in the world and 30\% of those are found in Africa, 15\% in the Americas, 32\% in Asia, 4\% in Europe, and 19\% in the Pacific (Harrow and Mpoche, 2008). Africa has some 800 languages and some estimates take the number to as many as 2400 (Kanana, 2013).

Ethiopia too, being a multicultural and multilingual state comprising more than 75 languages that can be categorized under four different language families viz. Semitic, Cushitic, Nilotic, and Omotic (Zahorik and Wondwosen, 2009) faces the problems that a multilingual society is forced to cope with and the multitudes of the languages in the country for long have been relegated to a less than equal status with Amharic, the language recognized as a lingua franca in the country. Hence, the purpose of this paper is to highlight the historical development of language policy in Ethiopia and assess how the language issue is being addressed currently, appraise the challenges that the current language policy in Ethiopia is facing, and suggest a possible solution. Accordingly, the subsequent sections are organized to deal with the materials and methods used in this piece, a theoretical discussion of the issue of language policy as it would have pertinent relevance to the discussion at hand, an overview of the language policies in the past regimes in Ethiopia, the current language policy in Ethiopia along with the challenge it is facing and, a possible way of dealing with the challenge. 


\section{The Issue of Language Policy}

The issue of language policy has for long been neglected in political theory and Kymlicka and Patten (2003) were the pioneers in the explicit analysis of language policy as such (Schmidt, 2004). The notion of language policy (LP) is related to decisions, rules, regulations and guidelines concerning the status, use, domains and territories of language, the rights of the speakers under consideration, the determination of whether a particular language(s) should have the status of recognition as a national language, language of wider communication, working language, language of instruction etc. As such, LP involves the development of public policies aimed at using the state's authority to influence various aspects of the status and use of language by people in a state (Schmidt, 2004). It is instigated by the time it is felt that the intervention of the state is required to determine the status and use of language in the society. In this regard, therefore, language policies and the classifications thereof differ from place to place and from time to time according to the political orientations of governments and the nature of the society in question. Accordingly, some governments have clear and explicit language policies called overt policies, which have written support in legal documents like the constitution. Others avoid this explicit approach and do not state their language policies in written legal documents, opting for covert language policies.

The other classification of language policies is based on the support and encouragement provided by the government in the use and development of languages, as either promotive or tolerant (permissive). Promotive policies encourage the development and use of one or several languages by giving some constitutional, administrative and legal guarantees or specifying the domain of use. Tolerant policies on the other hand, allow the use of a particular or several languages but there is no such encouragement of the use and development by providing financial or personnel support. In line with this, Patten (2001: 693-694) identified four more specific language policy models: disestablishment (public disengagement), official multilingualism, language rationalization, and language maintenance policies. While public disengagement policy (which is an implausible policy, for there should be some language(s) through which governmental services are provided) maintains that there should not be any publicly recognized official language, official multilingualism holds that there has to be some recognition of all the languages in a given country. On the other hand, language rationalization policy contends that there should be a privileged language that capitalizes on the denial or limitation of other languages. Finally, language maintenance policy advances the view of making all languages equally successful.

All the different types of policies stated are, therefore, manifestations of governments' policies as a function of their ideologies and other objective conditions in the society under consideration. As such, taking account of federations built up on multicultural and multilingual societies, the respective government's policies pertaining to language could be accommodative or not and this in turn affects the stability of the federation. Generally, language policies adopted by multiethnic states are informed by one of two major principles: the personality principle under which individuals can exercise the right to use their language of choice regardless of their geographic location and the territoriality principle where the right to exercise a given language is limited within the geographic boundaries of the group owning the language (Yonatan, 2009:504). The personality principle entails that individuals can obtain various services where ever they are within the boundaries of the state "where numbers warrant' and has the objective of nation-building by separating 'linguistic differences from collectivities, territories, and institutions which constitute them' (ibid: 505). And a common criticism against this policy is its tendency of perpetuating the dominant position of a historically dominant language (ibid.). Under a language policy informed by the territoriality principle, on the other hand, the official language would be the language of the majority in a given territory and individuals have the right to get services in that language only and as a result it is believed to promote unilingualism.

\section{An Overview of Language Policy in Ethiopia During the Imperial and the DERGUE REGIMES}

Ethiopia had no clear language policy before Haile Sellasie I (r.1930-1974), although it may not mean that there was no language policy at all; and some sources account that Amharic has been the official language in Ethiopia since 1270 (Wagaw, 2001). Emperor Tewodros II (r.1855-1868), who is credited for initiating the tide of centralization that created modern Ethiopia, had a promotive language policy that encouraged the use of Amharic; his main and noted contribution being his attempt to make it a literary language, changing the trend of using Geez in the writing of the royal chronicles into using Amharic. Although Tewodros' 'language policy' promoted Amharic from mere lingua franca to a 
literary language, it was only a covert one. The subsequent rulers, Yohannes IV (r.1872-1889) and Menelik II (r.1889-1913), too simply continued with this policy, where during the reign of Menelik II, Amharic reached the premises of local elites and administration offices where it had never been spoken before. Likewise, the language policy in Ethiopia under Haile Selassie's 1931 constitution was also a covert one in the sense that the constitution did not identify any language as having some kind of official status, other than the fact that the constitution itself was written in Amharic.

Remarkably, the 1955 Imperial constitution of Ethiopia, under article 125, declared Amharic to be the only official language of the Ethiopian empire and when Eritrea was fully integrated with Ethiopia in 1962, with the abolition of the 1952 federal arrangement, the official status of Amharic was also extended there. Hence, Ethiopia saw the first well established language policy in a written constitution during the reign of Emperor Haile Selassie I (Alemante, 2003). Haile Selassie's centralist zeal emphasized that homogenizing Ethiopian society was a prerequisite for the emergence of a strong unitary state. In this regard, language and history were seen as crucial tools. Accordingly, Amharic became the official language of the country and non-Amhara Ethiopians were obliged to study it. As Alemseged (2004) stated, outside the official arena too, people were directly and indirectly encouraged to abandon their own mother tongues in favor of Amharic under an intense policy of Amharization and this had clearly the goal of destructing ethnic peculiarities. To this end Alemseged Abay (2004:612) noted:

...Amharic was a crucial lethal tool in the death of ethnic peculiarities in the whole or in part...Its imposition as the official language has been a major source of grievance among those who did not speak it because in addition to the practical inconvenience of having to learn an alien language, it symbolized the ascendancy of an ethnic group to the helm of power.

The imperial regime of Haile Selassie I came to an end in 1974, partly as a result of its inability to accommodate and manage the ethno-linguistic diversity of the country. Emphasizing this, Aron P. Micheau (1996), stated that inequality and lack of integration of Ethiopians from different regional and ethnic backgrounds is significant and this is a phenomenon that distinguishes Ethiopia from many African and multiethnic societies; owing to this fact, resistance to the empire had become organized into groups that were mainly ethnic or regionally based.

Despite the criticism that the measures it took were 'either insufficient or lacked substance' (ibid.), the succeeding regime of the Dergue took commendable measures to deal with the ethnic diversity of Ethiopia that the current federal system is founded upon (See for instance the National Democratic Revolution Program declared by the Dergue in April 1976). The 1987 Peoples' Democratic Republic of Ethiopia (PDRE) constitution boldly reiterates that Ethiopia is a multinational state that existed for thousands of years (see the Preamble); that it is a country of nationalities that forged their unity through 'cultural intercourse, migrations, and similar interactions in times of peace as well as in times of war'. Moreover, Article 2(1) of the PDRE constitution states that Ethiopia is a '...unitary state in which all nationalities live in equality'. It also vowed, under Article 2(5), '... [to] ensure the development and respectability of the languages of the nationalities', hinting that the language policy is somehow promotive and that there would be official multilingualism. Nevertheless, article 116 of the PDRE constitution declared that 'Amharic is the working language in the People's Democratic Republic of Ethiopia'.

The Dergue initiated a national literacy campaign in about 15 languages, representing some $90 \%$ of the population, 'with the goal of literacy in the mother-tongue' and radio broadcasts were made in four other languages than Amharic (Wagaw, 2001:7). Hence, the Dergue's introduction of 15 Ethiopian languages (including Amharic), representing 90\% of the population, in the national literacy campaign can be seen as proto-type of an attempt to multilingualism. Nevertheless, though the 1987 constitution declared that the PDRE ensures the equality, respect and development of the nationality languages, practically there was no other Ethiopian language than Amharic, given any official status, save the use of a few languages in the literacy campaigns and radio broad casts. As such, some argue that the commitment of the Dergue to protect the rights of nationality groups was half-hearted, due to an apprehension of the perceived divisive implication of the national question (Mohammed, 2003). But most importantly, it was in the Dergue era that Amharic was constitutionally termed as the 'working language' of the government as opposed to its pre-1974 status as the 'official language' of the state (ibid.). 


\section{Language Policy in Federal Ethiopia and the Challenges}

The Tigray Peoples Liberation Front (TPLF) and the Oromo Liberation Front (OLF), the two chief ethnic movements behind the formation of the federal system in Ethiopia, considered the use of Amharic as the sole official language of government and instruction, in conjunction with the relatively greater visibility of Amharic-speaking officials at the higher levels of government in the days before the 1974 revolution, as a symbol of Amhara domination and the eventual extinction of the identities of other multitude ethnic groups (Alemante, 2003). This factor therefore, made the issue of language in Ethiopia important not only in its own right but also as a proxy for a plethora of other issues, namely cultural preservation, equal access to state power, and a redefinition of the identity of the state and the terms of its relationships with the different groups (ibid.).

In as much as language is one of the factors determining the peculiar identity of Nations and Nationalities and given the significant weight of the ethnic factor in the development of the Ethiopian federal system, it seems quite natural that policies affecting the language question, at all levels and purposes need to be compatible with the overall objectives and socio-political values of the constitutional system (Mohammed, 2003). Accordingly, there is no doubt that the Ethiopian federal system needs to attribute considerable significance to linguistic diversity and most interests associated with it. Historically in Ethiopia, as noted above, there was an attempt to use language as a medium of national integration. In the post-1991 period, however, linguistic difference is recognized as one of the legitimate grounds for social accommodation and sub-national autonomy (See articles 8, 39, and 46 of the Federal Democratic Republic of Ethiopia's constitution in particular). And noting this trend some are tempted to characterize the Ethiopian federal system as linguistic rather than the common designation of ethnic-based federal system (Cohen, 2003). As has already been touched upon elsewhere, it is important to note that the demand to resolve the language question in Ethiopia had its roots in the 1960s and there was an initiative towards accommodating ethnic and linguistic interests even during the last days of the imperial era (Mohammed, 2003). Therefore, the current official attitude towards accommodating linguistic diversity is not at all a new start. In this regard, Ivan Lukas (2007:107) noted that:

We can... say that the central government allows but does not guarantee the maintenance of minority language rights. There is undoubtedly a change regarding the official attitude of the central government to local languages; however, on the ground, due to practical constraints we can hardly speak of any dramatic turnaround in the LP [language policy] in Ethiopia. This results either in direct protest movements or accusing the central government of hypocrisy.

However, it can be clearly discerned that the introduction of written forms of regional and local languages and the use of those languages for official purposes and as media of instruction in the schools has become an issue of great political significance in Ethiopia since 1991 (Cohen, 2003). Hence, the current developments in the use of regional and local languages in Ethiopia are employed both to justify and also to criticize the federal structure's ability to ensure equality between Ethiopia's various ethnic or linguistic groups. On the one hand, it is welcomed as a positive change that counters previous patterns of language domination and as a facilitator of cultural self-expressions that were previously not possible. But, on the other hand, it is criticized for being inherently divisive (See for instance Ghelawdewos, 2012). Moreover, the opponents make the point that language development is costly and time consuming and is being implemented in a climate where the necessary material and human resources are insufficient (Cohen, 2003).

On the other side, it is contended that the introduction of several local languages is a manifestation of the rights of Nations, Nationalities and Peoples as enshrined under Article 39 of the Federal Democratic Republic of Ethiopia (FDRE) constitution. Moreover, it is regarded as a move for reversing the historical hegemony of Amharic and the consequent preoccupation with a form of domination often regarded as ethnic in character that demanded changes in official language use (Cohen, 2003). To this effect, the FDRE constitution articulates the right to self-determination in linguistic and cultural as well as political terms. Linguistically, the constitution expresses its respect for the collective worth and status of all ethnic groups' languages by declaring that '[a]ll Ethiopian languages shall enjoy equal state recognition' (Art. 5 of the FDRE Constitution). And this declaration seems to be in recognition of the fact that 'the most important rallying point around which the identities of Ethiopian ethnicities were formed was their language' thereby making the constitution consistent in its conviction that all the nations, nationalities, and peoples of Ethiopia enjoy sovereign 
equality (Lukas, 2007:106). In this vein, it is contended that linguistic security along with cultural preservation, is one of the underlying motives in the FDRE constitution (Alemante, 2003). And language is recognized as one of the constitutive elements of a national (ethnic) group with all the implied protected rights of such an entity (Mohammed, 2003).

It is argued that ethnic identity and ethnic affiliation is the basis for the current language and administrative policy in Ethiopia (Wagaw, 2001). However, the government has not formulated an official language policy that details the use of particular languages for defined purposes. Instead an implicit language policy exists as part of the government's wider federalist agenda and in the states of the FDRE three patterns of language use are observed (Cohen, 2003). First, there are the three states of the SNNPRS, Gambella, and Benishangul-Gumuz that followed the suit of the federal government in choosing Amharic as their working language due to their diverse ethnic constituencies. Second, there are those states that chose the dominant language in their respective states as the working language of their governments: Afar, Amhara, Oromia, Somali, and Tigray. In the third category is the State of Harari that chose Harari and Afaan Oromo together as the working languages (Assefa, 2003).

Although the FDRE constitution unequivocally recognizes all languages of Ethiopia as equal, a clear manifestation of the language policy is seen in the education sector. Section 3.5.1 of the Education and Training Policy of 1994 stated that 'cognizant of the pedagogical advantage of the child in learning in mother tongue and the rights of nationalities to promote the use of their languages, primary education will be given in nationality languages.' Hence, the primary argument in favor of education through mother tongue is pedagogic, that children learn to read and write more easily in a language they already speak, feel more included in the process of education and will as a result be more successful learners. Moreover, it is contended that the use of mother tongue in primary education increases students' ability to learn additional languages by increasing their confidence and learning capacity (Cohen, 2003). As such, most of the states have chosen the mother tongue spoken by the majority ethnic group in the particular state as the medium of instruction for primary education and therefore the right to mother tongue education is not enjoyed by all ethnic groups. In the major urban areas of Oromia, Amharic and Afaan Oromo are used optionally and there is a similar pattern of using Amharic alternatively with the dominant language in the state in the major urban areas of the SNNPRS, Tigray, Benishangul-Gumuz, Gambella, and Somali states. In many private primary schools in urban areas, especially in Addis Ababa, foreign languages, primarily English and in some schools French and Arabic, are used as media of instruction (Assefa, 2003). There is thus, substantial variation in the application of language policy in various contexts in Ethiopia. Nevertheless, despite the introduction of mother tongue education in different parts of the country, the quality of education in Ethiopia has kept on declining from year to year.

Therefore, the attempt to help develop the various languages in Ethiopia is not without negative consequences. Amharic speakers were relegated to less than equal status within some of the states and it is not uncommon to see bitter hatred of Amharic and people regarded as the owners of the language, considering Amharic as a 'colonial language'. As such, a policy of promoting one language or several may produce similar results in that it may stimulate senses of division and marginalization. Nevertheless, no matter what the effect is, the limited recognition of Amharic as the working language of the federal government and the declaration of the equality of all languages in Ethiopia by the 1995 federal constitution is hardly revolutionary. Though it is undeniable that the recognition of the equality of all languages by the central government has symbolic significance for the hitherto marginalized ethnic groups, the continued status of Amharic as the working language of the federal government is an arrangement that perpetuated the dominance of Amharic and the feeling that the other languages are of practically a secondary status.

There is still another formidable challenge to the current language policy in Ethiopia in that the multilingual policy that emphasized the ethnic identities of Ethiopians, promoting the hitherto relegated languages in the school system and in the sub-national bureaucracy in turn reduced the motive to learn Amharic among Ethiopians of various ethnic backgrounds. This is coupled with the fact that about $80 \%$ of Ethiopia's population still lives in rural areas and most of these peasants, except those living in the Amhara region, do not have any or have only little access to the lingua franca Amharic (Seidel and Moritz, 2009). As a result, currently Amharic is no more in the same footing as it was during the formative stages of the federal system and before, despite its continuance as the working language of the federal government. Hence, the assumption that was made 
while making the decision to make Amharic the working language of the federal government does not seem to be valid today in that the proportion of Ethiopians versed with and using Amharic has significantly diminished due to the opportunities in mother-tongue education. As such, Amharic is clearly having a restrictive impact for these Ethiopians in accessing various governmental services and employment particularly in federal jurisdictions. Also evidence from higher education institutions in Ethiopia depicts that the academic quality of the students has kept on declining despite the spread of mother tongue education, defying one of the primary objectives of the emphasis on mother tongue education.

Moreover, other than the precarious footing of Amharic as a lingua franca in the Ethiopian federal system, the current modality of language policy has neither satisfied the major ethnic groups in the country nor went in line with the desired constitutional goal of creating a sense of equality among the 'nations, nationalities, and peoples' of the country. It seems even to be driving the country in to what has been feared as the equivalent of 'the biblical tower of Babel' and in order to appreciate this reality it is sufficient to observe the situation in Ethiopia's universities often characterized as 'small Ethiopia'. In the universities, students coming from different ethnic backgrounds fail to barely communicate with one another let alone maintaining effective communications with each other as citizens of the same country. In this regard, de Villiers (2012: 342) noted that:

It is, however, recognized that in practice, young persons are in increasing numbers unable to converse fluently in Amharic and as a result the language-issue and recognition of the various other languages at the federal level and in the conduct of intergovernmental relations are likely to remain at the very forefront of Ethiopian politics.

The problem of communication becomes severe coupled with the fact that the students have a meager command of the English language, the medium of instruction in higher education in Ethiopia, owing to the ever deteriorating quality of education in the country. Hence, the argument that the continued dominance of Amharic at the federal level would be problematic is not without concrete evidence. The generation of post-1991 Ethiopia from many of the hitherto marginalized ethnic groups is a generation with a very poor command of spoken Amharic and almost no ability to write and read in it. It is also important to note that this inability of command of the Amharic language is not attributable much to the lack of opportunities to learn the language; but primarily the unwillingness to learn it by many, considering it as a language of domination. Hence, those scholars arguing that the fact that Amharic is the working language of the federal government is no impediment to access federal employment by Ethiopians of 'non-Amhara' background fail to notice this fact on the ground (See for instance Yonatan, 2009). Here it also needs to be emphasized that even both during the imperial and the Dergue regimes it was not the case that members of the other ethnic groups did not have access to high level governmental positions at all. Of course, during the imperial regime in particular, in order to hold such positions, one had to get assimilated to the dominant Amhara culture other than being a speaker of the Amharic language. During the Dergue regime, even cultural and ethnic affiliation was not an issue as such because, the nature of the system does not give primacy to those issues, save the official usage of Amharic out of the strong zeal to build a cohesive unitary state.

The argument that it would be rewarding to have a one common language that would serve as a lingua franca and a foundation for carving common national identity is compelling enough. In this regard, Amharic was chosen to serve the purpose and is still argued that it should continue doing so. However, it should also be noted that Amharic could hardly serve this purpose given the fact that it is considered as a language of historical domination and its diminishing status as a language of wider use in the country at large, for reasons explained above. Moreover, as language is one of the most important components of the ethnic identity of a given group and owing to the fact that the FDRE constitution pays extraordinary attention to language and if we could single out the most important factor behind the constitution, it certainly would be the language (Lukas, 2007:106), a claim for the recognition of one's language as a working language at the federal level can hardly be argued against, particularly under situations of state-sponsored identity politics like the one in Ethiopia.

Based on the fact that Amharic is viewed as a language of domination or that it can no longer serve as an effective lingua franca, as it was thought to be or otherwise, some groups are pushing for the recognition of other languages in parity with Amharic as federal working languages. Hence, the demand by many Oromo activists and political parties for the consideration of Afaan Oromo as an additional federal working language has justifiable bases both in constitutional and political terms. 
And the federal government has yet chosen to give deaf ears to the issue, may be realizing that once it begun to entertain such demands, there would be endless others that could be difficult to entertain. In this situation of turbulent ethnic politics that would not allow for the resolution of the problem of multilingualism either by continuing to use Amharic as a federal working language or considering additional languages, therefore, considering an alien language as another option seems to be compulsory.

In this regard, though Ethiopia does not have a colonial past, yet English is an official second language, having a prominent place in the linguistic profile of the country (Lanza, 2014).Therefore, there are compelling political and economic reasons for considering English as the official or working language of the federal government. Many African countries (including Rwanda, Burundi, and Gabon-all previously French Speaking countries) that were not colonized by Britain have recently adopted English as their official language not only considering it as a as a neutral option to the competition among local languages for official status; but also as a globally influential language of business, diplomacy, and education (Polonski et.al, 2013). In Ethiopia too, the adoption of English as a federal working language could iron out the ethnic divides in the federation and promote national unity. Moreover, adopting English as the working language of the federal government in Ethiopia would not only resolve the political quagmire surrounding language at home but also would make the country better equipped to benefit from the global capital market. This is of course recognizing the fact that English does not have sufficient social roots in Ethiopia, other than as a language of schooling; but at the same time noting that this problem could relatively be easily overcome in the near future as it is a common language of instruction in all the schools in Ethiopia.

\section{Conclusion}

Within a multilingual and multicultural setting, choosing one of the multitude languages and privileging it as the 'official national language' or even the 'working language' would inevitably symbolize the dominant status of its speakers. As such, owing to its multilingual nature, it could be rational to argue that Ethiopia needs one or more official languages in order to achieve political, economic, cultural and social integration. Hence, no matter how the exaltation of Amharic as the working language of the federal government in Ethiopia could be genuine in that it was solely meant to facilitate interactions across the board serving as a lingua franca, it cannot escape manipulations for political ends because it still symbolizes or at least reminds its dominant status and this is a fact that is despised by the elites of the hitherto marginalized ethnic groups. Moreover, the current status $q u o$ is also currently triggering demands by some groups for the official recognition of their particular ethnic group's language, a case in point being the claim of many Oromo parties and activists that Afaan Oromo should be recognized as the working language of the federal government in parity with Amharic.

However, the federal government has chosen to postpone the task of effectively dealing with the language politics in Ethiopia. Although the FDRE constitution declares the equal status of all of the country's languages, in reality they are not and cannot be equal, at least because promoting more than six dozens of languages equally is unmanageable. The constitution's declaration of Amharic as the working language of the federal government can be a manifestation of this problem. Hence, there is a blend of official multilingualism and language rationalization in the current language policy of Ethiopia, the FDRE constitution declaring that all the languages in the country have equal state recognition and at the same time exalting Amharic to the status of the working language of the federal government, owing to its historic dominance and wider use in the country. However, as the track record of this arrangement is unsatisfactory to both the centripetal and the centrifugal forces in the system, it is recommended to consider a neutral alien language, particularly English, as the language of the federal government for both compelling political and economic reasons.

\section{REFERENCES}

[1] Alemante G. Selassie (2003). Ethnic Federalism: Its promise and Pitfalls for Africa. The Yale Journal of International Law 28 (1), 51-107.

[2] Alemseged Abbay (2004). 'Diversity and State Building in Ethiopia', in African Affairs, 103(413), Royal African Society, pp593-614.

[3] Assefa Fiseha (2003). 'Theory Versus Practice in the Implementation of Ethiopia's Ethnic Federalism', in Ethnic Federalism the Ethiopian Experience in Comparative Perspective, David Turton (ed.), James curry Ltd., Addis Ababa University Press, Addis Ababa. 
[4] Cohen, Gideon (2003). 'The Development of Regional \& Local Languages in Ethiopia's Federal System', in Ethnic Federalism the Ethiopian Experience in Comparative Perspective, David Turton (ed.), James Curry Ltd., Addis Ababa University Press, Addis Ababa.

[5] de Villiers, Bertus. (2012). Creating Federal Regions - Minority Protection versus Sustainability ZaöRV 72 (2012), 309-351.

[6] Ghelawdewos Araia. (2012). What Language Should Ethiopians Speak? Columbia University, Institute of Education and Development for Africa, Inc.

[7] Harrow, Kenneth and Kizitus Mpoche (Eds.). (2008). Language, Literature and Education in Multicultural Societies: Collaborative Research on Africa, Cambridge Scholars Publishing.

[8] Kanana, Fridah Erastus. (2013). Examining African Languages as Tools for National Development: The Case of Kiswahili The Journal of Pan African Studies, vol.6, no.6, November 2013.

[9] Lanza, Elizabeth and Hirut Woldemariam. (2014). Multilingualism and Local Literacy Practices in Ethiopia: Language contact in regulated and unregulated spaces Multilingual Margins 2014, 1(1): $74-100$.

[10] Lukáš, Ivan. (2007). Language policy and process of nation-building in Ethiopia, Pp103-110. Available at: http://alppi.vedeckecasopisy.cz/publicFiles/00109.pdf

[11] Micheau, Aron P. (1996). The 1991 Transitional Charter of Ethiopia: A New Application of the Self-Determination Principle, 28 Case W. Res. J. Int'l L. 367 (1996) Available at: http://schola rlycommons.law.case.edu/jil/vol28/iss $2 / 4$

[12] Mohammed Habib. (2003). 'Federalism and Its Implications for the Language Question in Ethiopia' in First National conference on Federalism, Conflict and Peace Building, Addis Ababa: United Printers, pp243-251.

[13] Patten, Alan. (2001). Political Theory and Language Policy. Political Theory. Oct 2001, Vol. 29 Issue 5, p691. 25p.

[14] Polonski, Patrick et.al. (2013). Why are more African Countries adopting English as an Official Language? Paper Presented at African Studies Association Annual Conference, November 23, 2013 Baltimore, Maryland. Available at: https://www.booksforafrica.org/assets/documents/2013ASA-Conference---English-Language-in-Africa-PAPER.pdf

[15] Schmidt, Ronald Sr. (2004). Language Policy, Identity Politics and Political Theory. Conference Papers- Western Political Science Association, 2004, Annual Meeting, Portland, OR, p1-24. 24p. DOI: wpsa_proceeding_12623.PDF.

[16] Seidel, Katrin and Janine Moritz. (2009). Changes in Ethiopia's Language and Education Policy - Pioneering Reforms? In: Proceedings of the 16th International Conference of Ethiopian Studies, ed. by Svein Ege, Harald Aspen, Birhanu Teferra and Shiferaw Bekele, Trondheim 2009.

[17] Yonatan Tesfaye Fessha. (2009). A Tale Of Two Federations: Comparing Language Rights in South Africa and Ethiopia African Human Rights Law Journal, 2009(9), P501-523.

[18] Wagaw, Teshome G. (2001). 'The Conflict of Ethnic Identity and the Language of Education Policy in Contemporary Ethiopia'. International Conference on African Development Archives. Paper 31. http://scholarworks.wmich.edu/africancenter_icad_archive/31

[19] Zahorik, and Wondwosen. (2009). Debating Language Policy in Ethiopia, Asian and African Studies, 18, 2009, 1, 80-102.

Citation: Abiy Wondimeneh Lissanework. "The Quest for Multilingualism at the Center in the Ethiopian Federation and the Challenges of Entertainment." International Journal of Political Science (IJPS), vol 3, no. 3, 2017, pp. 1-8. doi:http://dx.doi.org/10.20431/2454-9452.0303001.

Copyright: () 2017 Authors. This is an open-access article distributed under the terms of the Creative Commons Attribution License, which permits unrestricted use, distribution, and reproduction in any medium, provided the original author and source are credited. 